\title{
THE RISK OF HYDROGEN EXPLOSION IN A SUBMARINE P.Z CATALYST BED FLOW RESISTANCE
}

Ryszard Kłos

Polish Naval Academy, Department of Underwater Work Technology in Gdynia, Poland

\section{ABSTRAC}

This series of articles presents the problem of undertaking the high risk project of modernisation of hydrogen incinerators on a submarine. The article describes technical issues connected with the flow capacity of a modernised hydrogen incinerator. Key words: flow resistance, scrubber filling flow resistance.

ARTICLE INFO

PolHypRes 2016 Vol. 57 Issue 4 pp. 7 - 18

ISSN: 1734-7009 eISSN: 2084-0535

DOI: 10.1515/phr-2016-0021

Pages: 12 , figures: 3 , tables: 2

page www of the periodical: www.phr.net.pl

Publisher

Polish Hyperbaric Medicine and Technology Society

\section{Original article}

Submission date: $14.09 .2016 \mathrm{r}$

Acceptance for print:20.10.2016r 


\section{INTRODUCTION}

Ventilation of battery compartments in which hydrogen emissions may occur on a submarine, can be implemented, inter alia, in a closed-circuit system with hydrogen combustion. It is realised through catalytic hydrogen combustion in the air. This article describes the partial objective of a project to modernise the catalyst bed flow resistance within a hydrogen incinerator via the implementation of new catalyst types. The choice of catalyst granulation was based on flow resistance.

Since catalyst granulation significantly differed in shape in the direction of a lower substitute diameter, the expected flow resistance of the bed was stronger. Increasing flow resistance of the catalyst deposits can reduce the efficiency of battery room ventilation on a submarine. This parameter should be maintained at a specified level, otherwise there is a risk of a need to redesign the incinerator equipment ${ }^{1}$ and thus increase the cost of modernisation.

Therefore, before taking the final decision on catalyst purchase, a sample of its base constituted by the alumina ${ }^{2}$ granulation was purchased for the purpose of carrying out flow resistance tests. The experiment proved that an increase of flow resistance $\Delta p$, connected with the application of a new filling, causes a flow reduction of $\dot{V}_{0}$ ventilation air at an acceptable level, guaranteeing the maintenance of ventilation capacity of battery rooms with the use of the same fan [1].

The measured results constitute the second paper in a cycle of articles illustrating the problematique of hydrogen explosion hazards on a submarine.

\section{INTRODUCTION}

Fluid dynamics is a branch of fluid mechanics dealing with forces causing fluid movement. The basic correlation describing the influence of forces on a Newtonian fluid movement is the Navier-Stokes equation. The Navier-Stokes equation constitutes a system of differential equations that set the principle for the determination of three-dimensional fluid velocity changes v over time t. The solution of the Navier-Stokes equation system was recognised as one of the seven most important mathematical "millennium problems", since despite thousands of works concerned with this subject matter that started to appear from the mid-nineteenth century, the regularity of solutions of the Navier-Stokes equation was not achieved.

\section{Flow rate}

When considering the flow through a selected thin-walled capillary with the unit length of $\mathrm{l}=1$, internal radius $r$ and external radius $R=r+d r$, with the axis direction coinciding with the flow direction, it is possible to assume for an extremely small $\mathrm{dr}$ that the speed of particles $v$ in the entire ring layer with the thickness of $d r$ is invariable $\mathrm{v}(\mathrm{dr})=$ idem - fig. 1 .

In concord with Newton's law, the force $F$ that acts on the area $A$ is, with accuracy of viscosity $\eta$, directly proportional to that area $A$ and velocity $v$ changes along its thickness (fig.2):

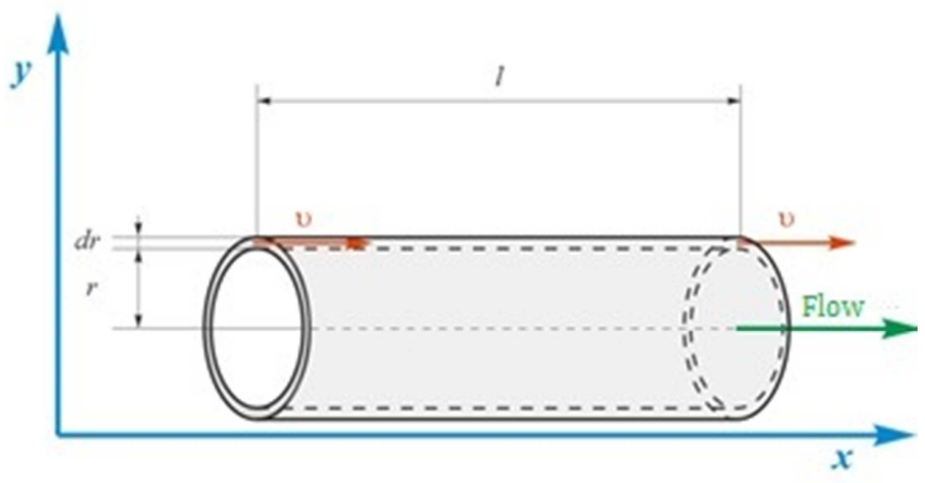

Fig.1.Capillary model.

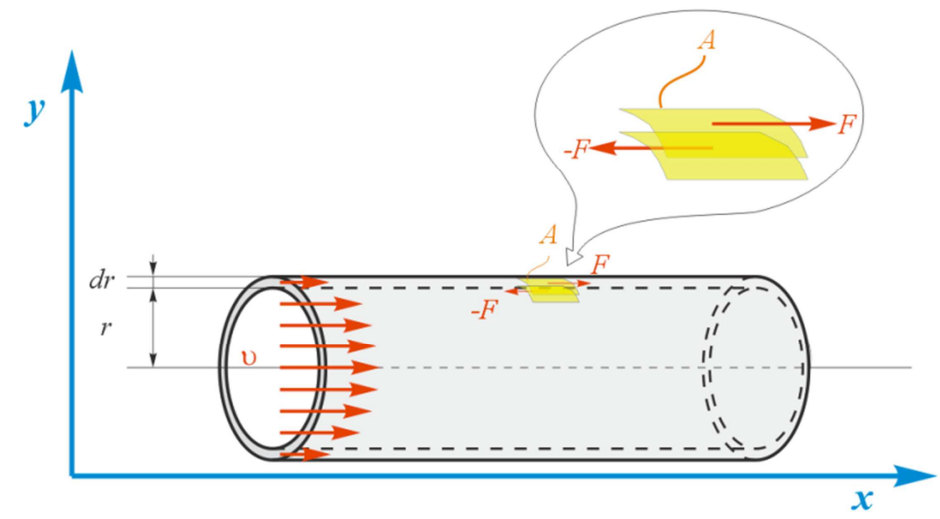

Fig. 2. Fluid motion in the capillary and force action on plane A. 


$$
F=\eta \cdot A \cdot \frac{d v}{d y}
$$

where: $F$-force acting on the area $A ; A$-surface area on which the force acts contiguously $F ; v$-particle velocity vertically to surface $A$; $y$-linear dimension

Thus, the force $F$ acting towards the flow direction, on the internal surface of the capillary can be expressed as the following equation: $F(r)=\eta \cdot 2 \cdot \pi \cdot r$. $\frac{d v}{d y}$. Due to the observed velocity $v^{3}$ change in Newtonian fluids in a plane transverse to flow direction, decreasing while moving away from the flow axis, then on the surface separated by a length of the radius $R$ a greater force should act of the same turn, however in the opposite direction $F(R)=-F-d F=-\eta \cdot 2 \cdot \pi \cdot r \cdot \frac{d v}{d y}-d(\eta \cdot 2$. $\left.\pi \cdot r \cdot \frac{d v}{d y}\right)-$ fig. 1 . Hence, for constant viscosity value

$$
F=-\eta \cdot 2 \cdot \pi \cdot d\left(r \cdot \frac{d v}{d y}\right)
$$

where: $r$-radius

There is a balance of forces in the defined motion. Therefore, friction force $T$ is counterbalanced by force $F$ resulting from the pressure drop $\Delta p$ at the terminal points of the external capillary surface, moving the interior surface of the considered stream in the shape of the capillary along the flow axis. According to the pressure definition $p=\frac{F}{A} \rightarrow F=p \cdot A$, it results that the force that causes particle movement inside the capillary will amount to:

$$
F=\Delta p \cdot A=\Delta p \cdot 2 \cdot \pi \cdot r \cdot d r
$$

where: $\Delta p$-pressure difference at a unit length of the capillary $l=1$

The balance of forces occurring in the defined movement described with equation (2) and (3) may be expressed as follows: $-\eta \cdot 2 \cdot \pi \cdot d\left(r \cdot \frac{d v}{d r}\right)=$ $=\Delta p \cdot 2 \cdot \pi \cdot r \cdot d r$, which, after rearrangement can be written as: $\frac{d}{d r}\left(r \cdot \frac{d v}{d r}\right)=-\frac{\Delta p}{\eta} \cdot r$. Next, by expansion of the left side with the use of the equation for function product differentiation, we will obtain the second-order linear differential equation: $r \cdot \frac{d^{2} v}{d^{2} r}+\frac{d v}{d r}=-\frac{\Delta p}{\eta} \cdot r$, which after rearrangement will assume the following form: $\frac{d^{2} v}{d^{2} r}+\frac{1}{r} \cdot \frac{d v}{d r}=-\frac{\Delta p}{\eta}$. With an introduction of a substitution: $y=\frac{d v}{d r}$ and $c=\frac{\Delta p}{\eta}$ we may lower the order of the differential equation, thus obtaining the first-order linear differential equation: $\frac{d y}{d r}+\frac{y}{r}-c=0$.

We may check that the solution to this equation will be the function: $y=\frac{\text { const }}{r}-r \cdot \frac{c}{2}$. Again, by using substitution $y=\frac{d v}{d r}$ and $c=\frac{\Delta p}{\eta}$, we obtain: $\frac{d v}{d r}=\frac{\text { const }}{r}-r$. $\frac{\Delta p}{2 \cdot \eta}$. If we integrate the thus obtained equation, the solution will be as follows: $v=$ const $\cdot \ln r-\frac{\Delta p}{4 \cdot \eta} \cdot \frac{r}{2}+$ const'. For zero internal capillary radius $r=0$ the achieved motion movement will be maximal $v_{\max }$, hence const $\equiv 0, \quad$ as otherwise the value $\ln r$ will be undetermined. Therefore, the solution is reduced to a general function $v=-\frac{\Delta p}{4 \cdot \eta} \cdot r+$ const $^{\prime}$, for which the flow rate at the external surface will be equal to zero
$\forall_{R=r+d r} v=0$, and thus const ${ }^{\prime}=\frac{\Delta p}{4 \cdot \eta} \cdot R^{2}$. In the end, the flow rate $v$ inside the capillary, in the function of its radius $R$ at the $r$ distance from the centre can be expressed as the following equation:

$$
v=\frac{\Delta p}{4 \cdot \eta} \cdot\left(R^{2}-r^{2}\right)
$$

\section{Average flow rate}

The average flow rate $\bar{v}$ can be approximated with the arithmetic average: $\bar{v}=\frac{v(r=0)-v(r=R)}{2}$. According to equation (4), the flow rate value at the capillary wall by definition is equal to zero: $v(r=R) \stackrel{\text { def }}{=} 0$. At the capillary axis it reaches the maximum value: $v(r=0)=\frac{\Delta p}{4 \cdot \eta \cdot l} \cdot R^{2}$. Hence the average rate $\bar{v}$ will amount to [2]:

$$
\bar{v}=\frac{\Delta p}{8 \cdot \eta \cdot l} \cdot R^{2}
$$

where: $\bar{v}$-average particle velocity; $l$ - capillary length

The Poiseuille Equation

If we transform equation (5) into the following form:

$$
\Delta p=\frac{32 \cdot \eta \cdot l \cdot \bar{v}}{D}
$$

where: $D$-capillary diameter

we can obtain a general representation of the flow through a capillary. Equation (6), describing approximate flow resistances observed as a pressure drop $\Delta p$ in a horizontal duct with a constant circular cross section up to the diameter of $D$, for laminar flows, is known as the Poiseuille equation.

\section{The Darcy-Weisbach Equation}

By an introduction of Reynolds number $\operatorname{Re}=\frac{\overline{\mathrm{v}} \cdot \mathrm{D} \cdot \rho}{\eta}$ equation (6) can be further developed to a more popular form of the Poiseuille equation, known as the Darcy-Weisbach equation: $\Delta \mathrm{p}=\frac{\overline{\mathrm{v}} \cdot \mathrm{D} \cdot \rho}{\eta} \cdot \frac{1}{\operatorname{Re}} \cdot \frac{2}{2} \cdot \frac{32 \cdot \eta \cdot \mathrm{l} \cdot \overline{\mathrm{v}}}{\mathrm{D}}$. Through ordering we can obtain a generally known form of the Darcy-Weisbach equation:

$$
\Delta p=\lambda \cdot \frac{l}{D} \cdot \rho \cdot \frac{\bar{v}^{2}}{2} \mid \lambda=\frac{64}{R e} \wedge \operatorname{Re}=\frac{\bar{v} \cdot D \cdot \rho}{\eta}
$$

where: $\lambda$-dimensionless resistance coefficient; Re-Reynolds number; $\rho$-density

The Darcy-Weisbach equation describing approximate flow resistances observed as a pressure drop $\Delta \mathrm{p}$ in a horizontal duct with a constant circular cross section up to an average diameter of $\mathrm{D}$, for laminar flows conditioned by Reynolds number value Re.

\section{FLOW RESISTANCE DETERMINATION}

The resistance observed in a hydrogen incinerator includes that resulting from its construction and the filling 5 . However, the first is usually considered as 
negligible.

The resistance of the filling is calculated according to a model in the form of the Darcy-Weisbach equation modified with bed parameters [3]:

$$
\Delta p=\lambda_{f}^{\prime} \cdot \frac{\bar{v}^{2}}{2 \cdot \varepsilon^{2}} \cdot \rho \cdot \frac{1}{d_{h}}
$$

where: $\Delta p$-fluid pressure drop during flow through a bed with the height of $l$ and hydraulic diameter of $d_{h}[\mathrm{~Pa}]$; dimensionless resistance coefficient $\lambda_{f}^{\prime}$, where $\lambda_{f}^{\prime}=f(R e)$ stands for Reynolds number; Re average fluid velocity in relation to the entire absorbent cross-section $[\bar{v}-], \quad m \cdot s^{-1}$ bed porosity $[\varepsilon-] ; \mathrm{m}^{3} \cdot \mathrm{m}^{-3}$ fluid density $[\rho-] ; \mathrm{kg} \cdot \mathrm{m}^{-3}$ hydraulic diameter $\left[d_{h}-\right] m$

Bed porosity $\varepsilon$ is the ratio of the volume of all the free spaces $V_{w}$ to the volume taken up by dry material $V: \varepsilon=\frac{V_{w}}{V}$. Hydraulic diameter $d_{h}$ can be defined with the following equation:

$$
d_{h}=4 \cdot r_{h}=4 \cdot \frac{V_{w}}{S}
$$

where: $r_{h}$-hydraulic radius of the duct $[\mathrm{m}] ; S$-total area of the filling $\left[\mathrm{m}^{2}\right]$

The volume taken up by dry material $V_{s}$ can be expressed with the use of the porosity definition $\varepsilon$ with the equation: $V_{s}=V-V_{w}=(1-\varepsilon) \cdot V$. Thus, equation (9) can also be expressed as:

$$
d_{h}=4 \cdot \frac{\varepsilon}{1-\varepsilon} \cdot \frac{V_{s}}{S}
$$

where: $V_{s}$-dry material volume

Commonly, the average diameter of the particles of a given filling is determined according to Sauter. It consists in a replacement of a set of particles with the total volume $V_{S}$ and area $S$, with the same number of spheres with an identical diameter $d_{s}$, whose relation of the total volume $V_{S}$ to the area $S$ is the same as that of the considered set [4]:

$$
\left.\begin{array}{l}
V_{s}=n_{p} \cdot \frac{\pi}{6} \cdot d_{s}^{3} \\
S=n_{p} \cdot \pi \cdot d_{s}^{2}
\end{array}\right\} d_{s}=6 \cdot \frac{V_{s}}{S}
$$

where: $n_{p}$-number of spheres, $d_{s}$-particle diameter of a given set acc. to Sauter $[\mathrm{m}], V_{s}$-total volume acc. to Sauter $\left[\mathrm{m}^{3}\right], S$-total area acc. to Sauter $\left[\mathrm{m}^{2}\right]$

From equations (11) and (10) it results that:

$$
d_{h}=\frac{2}{3} \cdot \frac{\varepsilon}{1-\varepsilon} \cdot d_{s}
$$

The resistance coefficient $\lambda_{f}^{\prime}$ for granules $^{6}$ according to Ergun can be expressed as [3]:

$$
\begin{gathered}
\lambda_{f}^{\prime}=\frac{4}{3} \cdot \lambda_{f} \\
\lambda_{f}=\frac{a}{R e}+1,75 \mid 1 \leq R e \leq 3000 \\
R e=\frac{1}{1-\varepsilon} \cdot \frac{\bar{v} \cdot \rho \cdot d_{s}}{\eta}
\end{gathered}
$$

where: $a$-dimensionless empirical coefficient ${ }^{7}[1]$; Re - Reynolds number [1]; $\eta$-dynamic viscosity of the flowing fluid $[\mathrm{Pa} \cdot \mathrm{s}]$
The resistance coefficient $\lambda_{f}^{\prime}$ for laminar flows according to Blake-Kozeny can be expressed as [3]:

$$
\left\{\begin{array}{c}
\lambda_{f}^{\prime}=\frac{4}{3} \cdot \lambda_{f} \\
\lambda_{f}=\frac{a}{R e} \\
R e=\frac{1}{1-\varepsilon} \cdot \frac{\bar{v} \cdot \rho \cdot d_{s}}{\eta}
\end{array}\right.
$$

From equations (8), (12) and (14) it results that:

$$
\Delta p=\frac{4}{9} \cdot \frac{a}{\varepsilon} \cdot \eta \cdot\left(\frac{l}{d_{h}}\right)^{2} \cdot \frac{\bar{v}}{l}
$$

where: $l$-bed height $[\mathrm{m}]$ results that:

Compliant with the stream continuity law it

$$
\dot{V}=A \cdot v=\frac{V}{l} \cdot v \Rightarrow \frac{v}{l}=\frac{\dot{V}}{V}
$$

where: $\dot{V}$-volumetric flow rate $\left[\mathrm{m}^{3} \cdot \mathrm{s}^{-1}\right] ; A$-cross-section of the stream $\left[\mathrm{m}^{2}\right] ; V$-bed volume $\left[\mathrm{m}^{3}\right]$

Thus, equation (15) can be transformed into the following form:

$$
\left(\frac{l}{d_{h}}\right)^{2}=\frac{9}{4} \cdot \frac{\varepsilon}{a} \cdot \frac{\Delta p}{\eta} \cdot\left(\frac{V}{\dot{V}}\right)
$$

Next, by transforming formula (17) we obtain:

$$
\frac{l}{d_{h}}=\frac{3}{2} \cdot \sqrt{\frac{\varepsilon}{a \cdot \eta}} \cdot \sqrt{\frac{\Delta p}{\dot{V}} \cdot V}
$$

In concord with Sonine's first integral in kinetic gas theory, dynamic viscosity is expressed with the following equation: $\eta=\frac{1}{\pi \cdot \delta^{2}} \cdot\left(\frac{\mathrm{m} \cdot \mathrm{k} \cdot \mathrm{T}}{6}\right)^{0,5}$, where: $\delta$ stands for the effective diameter of an ideal gas particle, $m$ is gas mass, $\mathrm{k}$ means Boltzmann constant and $\mathrm{T}$ temperature $[5,6]$. Dynamic viscosity $\eta$ is a function of temperature $\eta=f(T)$, however does not depend on pressure $\eta \neq f(p)$, hence equation (18) can be simplified to the following form:

$$
\sqrt{\Delta p}=\text { const } \cdot \dot{V}
$$


a)

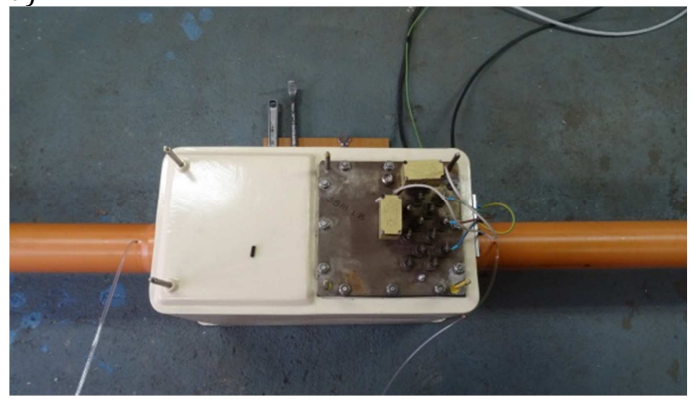

c)

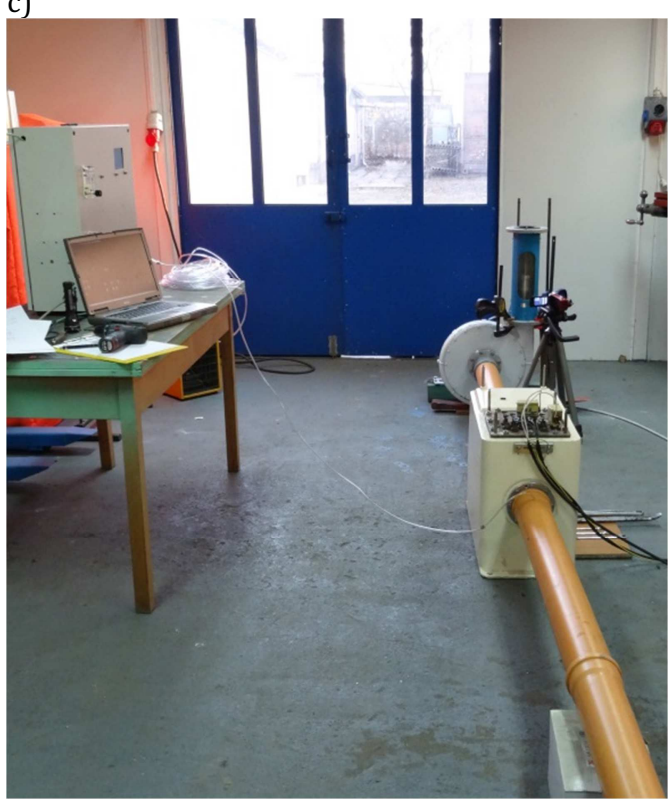

b)

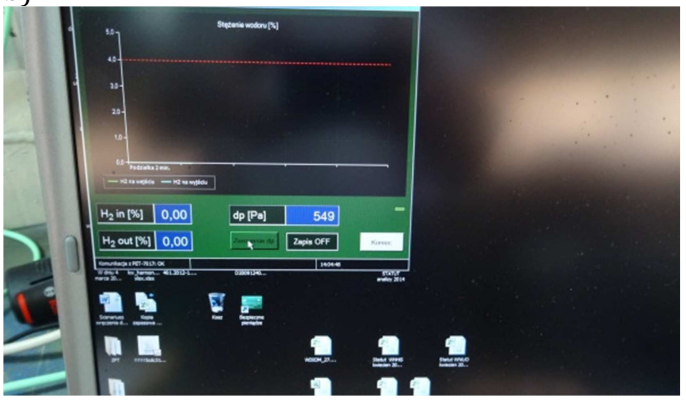

d) กา

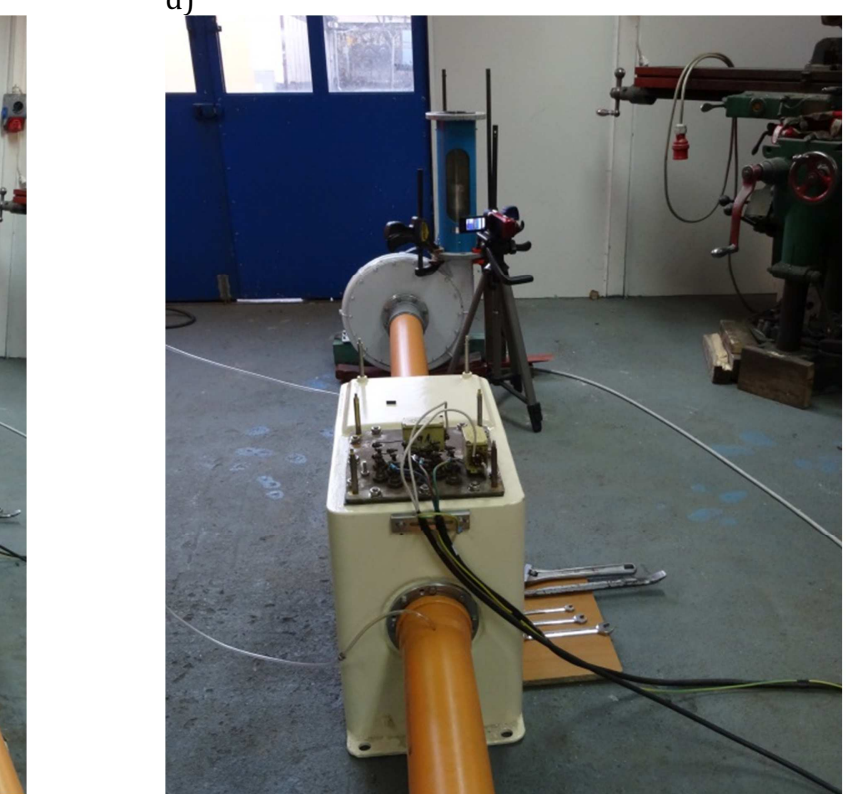

Fig 1. The measuring station for determining flow resistance by $P D-3 A$ hydrogen incinerator: a)probe connection to pressure measurement: b)indications of the measuring system; c)a complete measuring station for flow resistance determination; d)the examined installation for battery compartment ventilation removed from a submarine, in the background we can see the fan and rotameter for air stream control.

a)

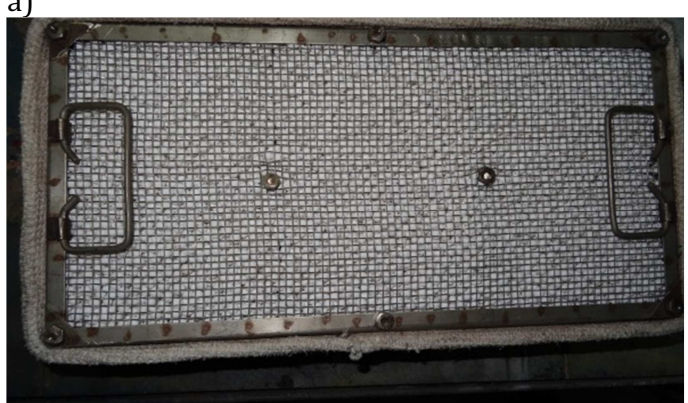

b)

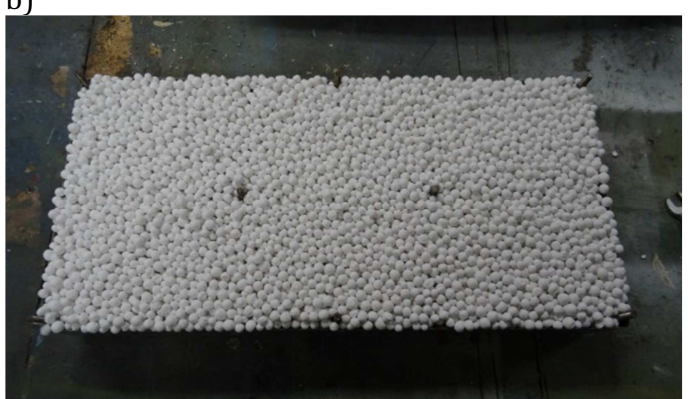

Fig. 2. Frame of $P D-3 A$ hydrogen incinerator catalyst: a)assembled and prepared for insertion into the hydrogen incinerator; b)filled before closing the upper cover. 
Parameter

\begin{tabular}{l}
\hline Metal content in matrix $\mathrm{Al}_{2} \mathrm{O}_{3}$ \\
\hline Catalytic deposit density \\
\hline Bulk density \\
\hline Substitute diameter \\
\hline Statistical efficiency of hydrogen oxidation exceeds $100^{\circ} \mathrm{C}$ \\
\hline Catalyst production is based on the use of pellets $\mathrm{Al}_{2} \mathrm{O}_{3}$ with the diameter \\
of $\phi \in[4 ; 8] \mathrm{mm}$, however there is a fluctuation in the size of the pellets delivered by \\
the manufacturer
\end{tabular}

From equation (20) it results that the square root of the pressure drop $\sqrt{\Delta p}$ of the gas mixture flowing through the reactor's filling constitutes a linear function of the volumetric flow rate $\dot{V}{ }^{8}$. The flow resistance $\Delta p$ measurement results ${ }^{9}$ for the reactor filling in the function of a gas mixture stream $\dot{V}$ performed at the station are shown in fig.1.

The frame structure for the hydrogen combustion reactor is shown in fig. 2 . The reactor has been filled with four layers of the catalytic bed enclosed with frames having a height of approx. $h \cong 7 \mathrm{~cm}$ and base dimensions of approx. $A^{\text {a }} \cong(39.5 \times 19 \times 7) \mathrm{cm}$, which adds up to the volume of the catalyst bed at the level of ca. $V \cong 5.25 \mathrm{dm}^{3}$. The manufacturer declares the bulk density to be $d \cong 0.8 \mathrm{~kg} \cdot \mathrm{dm}^{-3}$ this gives ca. $m \cong 4.2 \mathrm{~kg}$ of catalyst mass. The tests have been conducted with a catalyst applied on alumina matrix $\mathrm{Al}_{2} \mathrm{O}_{3}$ in the form of spheres with the diameter $\phi$ contained with the limits $\phi \in[4 ; 8] \mathrm{mm}$. According to the manufacturer's information, the catalyst has the properties specified in tab.1.

As mentioned before, a significant catalyst parameter from the point of view of its replacement consist in the flow resistances $\Delta p$ exerted by it. The value of the root of resistance flow $\sqrt{\Delta p}$ in the function of the flowing air stream was measured with the described equipment $\dot{V}_{0}-$ tab. 2 and fig. 2 .

Flow resistance $\Delta p$ exerted by the hydrogen incineration reactor in a function of the air stream $\dot{V}$ in selected catalyst bed configurations.

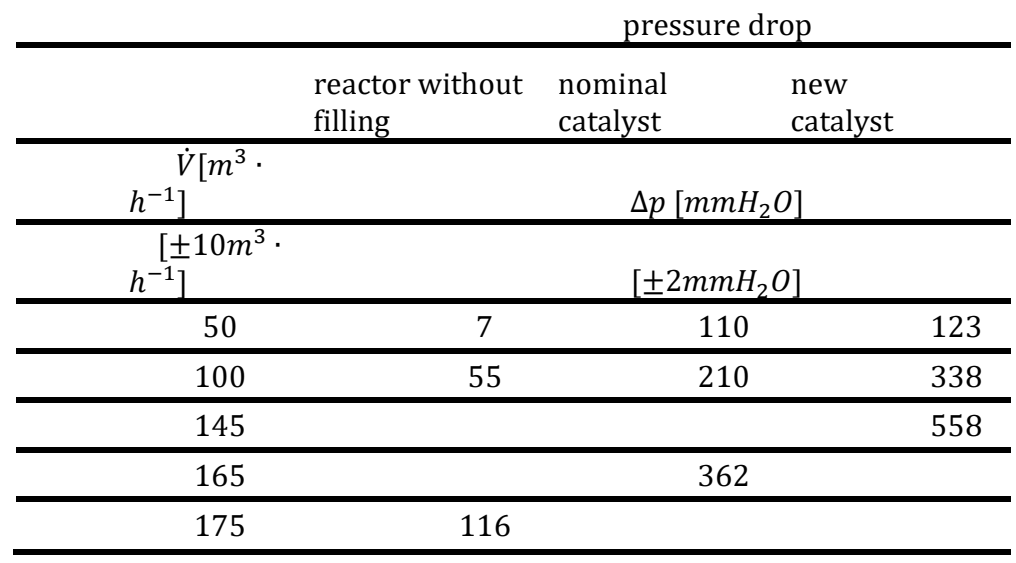




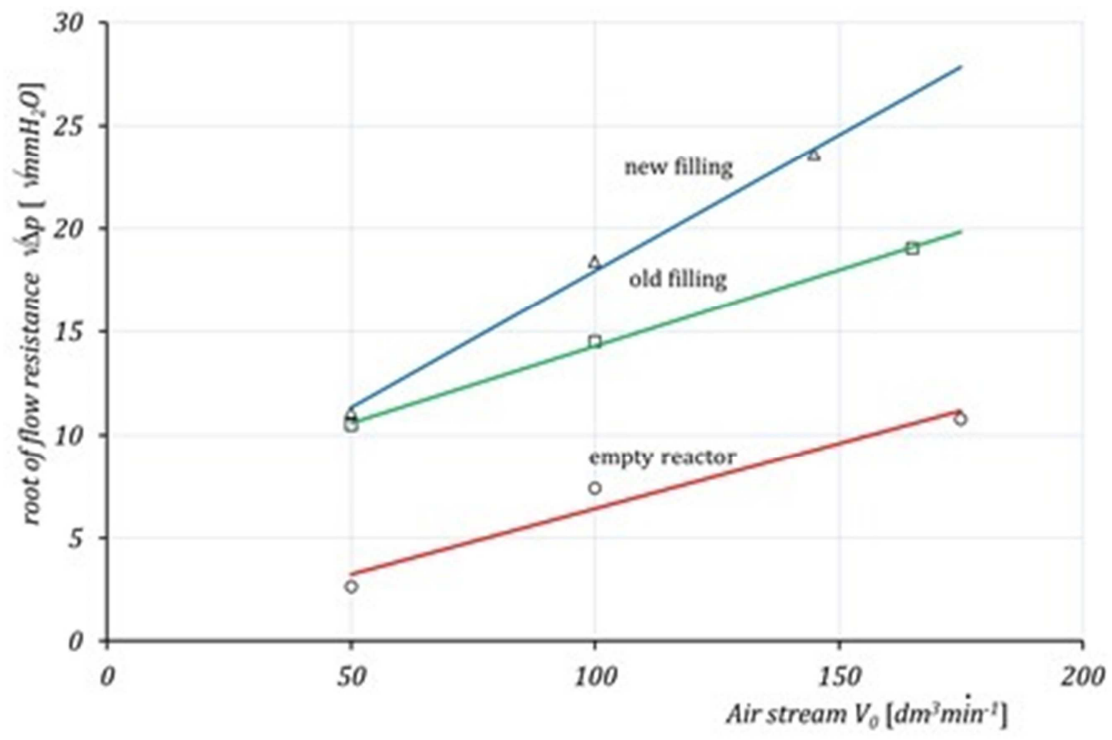

Fig. 3. Root of the flow resistance $\sqrt{\Delta p}$ exerted by hydrogen incineration reactor in a function of the air stream $\dot{V}_{0}$ flowing in normal conditions in selected catalyst bed configurations.

The experiment proved that, an increase of flow resistance $\Delta p$, connected with the application of a new filling causes a flow reduction in ventilation air $\dot{V}_{0}$ at an acceptable level, guaranteeing preservation of battery compartment ventilation capacity with the use of the same fan, as described in the first article of the cycle.

\section{ConClusion}

The results of tests, described in the first article of the cycle on catalysis, revealed that it suffices if the modernisation of hydrogen incinerators involves the replacement of only half of the catalyst. Therefore, the cartridge of the incinerator consisted of two pallets with traditional cartridge, one with a palladium catalytic converter $G A-50 P d, \quad 0.5 \%_{m} P d$ and one pallet with platinum catalyst $G A-20 P t, \quad 0.5 \%{ }_{m} P t$. With the proposed catalytic bed configuration, it is possible to obtain practically zero hydrogen concentration level at the incinerator outlet with its inflow concentration reaching $C_{\mathrm{H}_{2}} \cong 3 \%_{v}$. Zero hydrogen content level obtained repeatedly at the incinerator outlet is a result that significantly exceeds the initial quality requirements $C T Q^{10}$ for acceptance tests.

The proposed bed configuration would not only allow saving resources for catalyst purchase but also minimising flow resistances exerted by a complete catalyst bed, since only half of it is in the granulation that increases the flow resistance. Partial filling of pallets with new catalysts enables us to maintain ventilation at only a slightly lowered level than the required stream: $\dot{V}_{0} \cong 140 \mathrm{~m}^{3} \cdot h^{-1}$. Consequently, this will allow us to maintain the thus far implemented construction of hydrogen incinerators.

\section{BIBLIOGRAPHY}

1. Kłos R. 2015. Catalytic combustion of hydrogen in a submarine. Gdynia : Polskie Towarzystwo Medycyny i Techniki Hiperbarycznej, 2015. ISBN 978-83-938-322-3-1

Batuner Ł.M., Pozin M.J. 1956. Mathematical methods in chemical technique. Warsaw : Państwowe Wydawnictwa Techniczne, 1956. 517.62. Pohorecki R., Wroński S. 1977. Kinetics and thermodynamics of chemical engineering processes. Warsaw : WNT, 1977. Kłos R. 2008. Life sustaining systems in a submarine. Gdynia : Polskie towarzystwo medycyny i Techniki Hiperbarycznej, 2008. p. 163. ISBN 978-83-924989-4-0

5. Gumiński K., Petelenz P. 1989. Elements of theoretical chemistry. Warsaw : Państwowe Wydawnictwo Naukowe, 1989. ISBN 83-01-08109-0

6. Garzó V., Santos A. 2003. Kinetic Theory of Gases in Shear Flows: Nonlinear Transport. Dordrecht: Springer Science+Business Media Netherlands, 2003. Vol. Fundamental Theories of Physics 131. 978-90-481-6347-2, 978-94-017-0291-1, DOI 10.1007/978-94-017-0291-1

dr hab. inż. Ryszard Kłos, prof. nadzw. AMW

Akademia Marynarki Wojennej im. Bohaterów Westerplatte Zakład Technologii Prac Podwodnych 81 - 103 Gdynia 3, ul. Śmidowicza 69 Tel: +5862627 46, Fax: +586262761

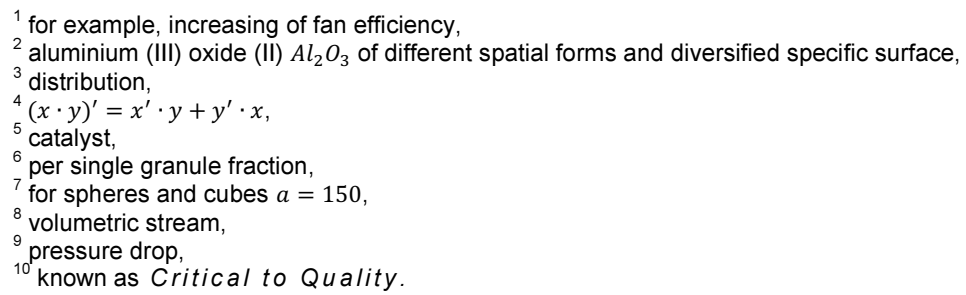

